\title{
Catalytic performance of $\mathrm{Cu}$ - and $\mathrm{Zr}$-modified beta zeolite catalysts in the methylation of 2-methylnaphthalene
}

\author{
Fatih Güleç $^{1}$. Farooq Sher ${ }^{1} \cdot$ Ali Karaduman $^{2}$
}

Received: 9 January 2018 / Published online: 22 November 2018

(C) The Author(s) 2018

\begin{abstract}
2,6-Dimethylnaphthalene (2,6-DMN) is a commercially important chemical for the production of polyethylenenaphthalate and polybutylene naphthalate. However, its complex synthesis procedure and high production cost significantly reduce the use of 2,6-DMN. In this study, the synthesis of 2,6-DMN was investigated with methylation of 2-methylnaphthalene (2$\mathrm{MN}$ ) over metal-loaded beta zeolite catalysts including beta zeolite, $\mathrm{Cu}$-impregnated beta zeolite and $\mathrm{Zr}$-impregnated beta zeolite. The experiments were performed in a fixed-bed reactor at atmospheric pressure under a nitrogen atmosphere. The reactor was operated at a temperature range of $400-500{ }^{\circ} \mathrm{C}$ and varying weight hourly space velocity between 1 and $3 \mathrm{~h}^{-1}$. The results demonstrated that 2,6-DMN can be synthesized by methylation of 2-MN over beta type zeolite catalysts. Besides 2,6-DMN, the product stream also contained other DMN isomers such as 2,7-DMN, 1,3-DMN, 1,2-DMN and 2,3DMN. The activity and selectivity of beta zeolite catalyst were remarkably enhanced by $\mathrm{Zr}$ impregnation, whereas $\mathrm{Cu}$ modification of beta zeolite catalyst had an insignificant effect on its selectivity. The highest conversion of 2-MN reached $81 \%$, the highest ratio of 2,6-DMN/2,7-DMN reached 2.6 and the highest selectivity of 2,6-DMN was found to be $20 \%$ by using $\mathrm{Zr}$-modified beta zeolite catalyst.
\end{abstract}

Keywords Methylation $\cdot$ Naphthalene derivatives $\cdot$ Polyethylenenaphthalate $\cdot 2,6$-Dimethylnaphthalene and beta zeolite catalyst

\section{Introduction}

2,6-Dimethylnaphthalene (2,6-DMN) is a crucial chemical as a feedstock material for the production of high-performance polyester resins such as polyethylenenaphthalate (PEN) and polybutylene naphthalate $(\mathrm{PBN})$. There are many expected PEN applications in film and bottle uses, refillable bottles, advanced photosystems and tire codes (Motoyuki et al. 2000). PEN shows good thermal and mechanical stability (Pu and Inui 1996) and superior properties such as higher gas barrier, tensile strength, heat

Edited by Xiu-Qin Zhu

Fatih Güleç

Fatih.Gulec@nottingham.ac.uk

1 Department of Chemical and Environmental Engineering, University of Nottingham, University Park,

Nottingham NG7 2RD, UK

2 Department of Chemical Engineering, Faculty of Engineering, Ankara University, Ankara 06100, Turkey resistance and stability against UV light and X-rays in comparison with polyethylene terephthalate (PET) (Güleç et al. 2016, 2017). The main applications of PBN are expected to be for electronics, insulators and car parts (Motoyuki et al. 2000). However, due to the complex synthesis procedures and lack of effective process for the commercial synthesis of 2,6-DMN, PEN and PBN have not been widely used in industrial applications (Motoyuki et al. 2000; Niftaliyeva et al. 2015; Güleç et al. 2016). To produce 2,6-DMN, a few synthesis procedures have been developed such as methylation (Pu and Inui 1996; Park et al. 2002, 2005; Jin et al. 2006, 2008; Song et al. 2007; Zhang et al. 2007; Zhao et al. 2008; Bai et al. 2009; Liang et al. 2010), disproportionation (Niftaliyeva and Karaduman 2015; Güleç et al. 2016), alkylation (Fraenkel et al. 1986) and isomerization (Motoyuki et al. 2000; Ferino et al. 1996) with a naphthalene or methylnaphthalene sources.

Direct synthesis of 2,6-DMN has been investigated by methylation and disproportionation of naphthalene sources over different kind of zeolite catalysts such as Pt-, Fe-, Ti-, 
Zr- and Co-modified ZSM-5, ZSM-12 and La, Cu-doped Y zeolite by (Jin et al. 2008). Pu and Inui (1996) studied the methylation of 2-MN over zeolite catalysts including ZSM5, Fe-MFI, Zn-MFI and Pt/ZSM-5 in a fixed-bed flow reactor. Fe- and Zn-modified MFI silicates showed higher $2,6-\mathrm{DMN} / 2,7-\mathrm{DMN}$ ratios and higher $\beta, \beta$-DMN selectivity compared with ZSM-5. On the other hand, the metal silicates demonstrated lower methylnaphthalene conversion and faster deactivation than ZSM-5. However, Jin et al. (2008) investigated the methylation of 2-MN over modified ZSM-5 type zeolite catalyst in a fixed-bed micro-reactor at $400{ }^{\circ} \mathrm{C}$ with a reactant mixture of $2-\mathrm{MN}$, methanol and mesitylene having a molar ratio of 1:5:3, respectively. Both catalytic activity and lifetime of ZSM-5 zeolite catalyst were improved by $\mathrm{NaOH}$ treatment. Additionally, a higher 2,6-DMN/2,7-DMN ratio, higher selectivity and higher yield of 2,6-DMN were obtained over Zr-modified mesoporous ZSM-5. The disproportionation of 2-MN over $\mathrm{Zr}$ modified ZSM-5 zeolite catalyst in a fixed-bed reactor at $400-450{ }^{\circ} \mathrm{C}$ has been investigated for five different weight hourly space velocities by (Güleç et al. 2016). The results revealed that $\mathrm{Zr}$-modified ZSM-5 improved the catalytic activity of ZSM-5 in the disproportionation reaction. Furthermore, Liang et al. (2010) mentioned that Pt-modified ZSM-5 catalyst showed lower coke formation, higher conversion of 2-MN, higher selectivity and higher yield of 2,6-DMN compare with HZSM-5. In another study, Niftaliyeva and Karaduman (2015) investigated the methylation of 2-MN over $\mathrm{Cu}$ - and La-impregnated $\mathrm{Y}$ zeolite catalyst using a feed mixture of $2 \mathrm{MN}$, methanol and 1,3,5trimethylbenzene having a molar ratio of 1:5:5. The type $\mathrm{Y}$ zeolite catalyst resulted in a very high conversion of 2-MN. Moreover, La impregnation enhanced the conversion activity of Y zeolite catalyst. Although 2-MN is one of the widely used raw material in the production of 2,6-DMN, whereas naphthalene is also another alternative starting material. Wu et al. (2010) established the effect of $\mathrm{Al}, \mathrm{Ga}$ and $\mathrm{Al} / \mathrm{Ga}$ impregnated $\mathrm{ZSM}-12$ on the methylation reaction of naphthalene. According to their results, the highest conversion of naphthalene was obtained over Al/Ga-modified ZSM-12 and the highest 2,6-DMN percentage and highest 2,6-DMN/2,7/DMN ratio were also observed over Ga-modified ZSM-12. Song et al. (2007) investigated shape selective methylation of naphthalene for the synthesis of 2,6-DMN with Ti-, Co- and Fe-modified ZSM-5 zeolite catalyst. The results illustrated that the highest conversion of naphthalene, the highest percentage of 2,6DMN and highest 2,6-DMN/2,7/DMN ratio obtained over Fe-impregnated ZSM-5 as compared with Ti- and Comodified ZSM-5. The synthesis of 2,6-DMN with isomerization reaction was studied by Motoyuki et al. (2000) and they investigated isomerization of DMN isomers to produce 2,6-DMN. According to their results, an effective synthesis process of 2,6-DMN is possible by utilizing a non-valuable feed stream that mainly includes naphthalene and DMN isomers. In addition, isomerization reaction of the mixture of DMN isomers occurred over MCM-22 zeolite catalyst. The isomerization reaction also showed that 2,6-DMN can be enriched in the mixture effectively.

Although there have been a few studies on the synthesis of 2,6-DMN, the desired values and economical process have not yet been developed. The catalysts used in the methylation reaction play an important role in the synthesis procedure to achieve high 2,6-DMN selectivity. Therefore, a catalyst such as beta zeolite can be used in both methylation (Park et al. 2002; Van der Mynsbrugge et al. 2012) and isomerization (Wang et al. 1997; Motoyuki et al. 2000) processes and could give higher selectivity for specific DMN isomers. In previous studies, neither $\mathrm{Cu}$ - nor $\mathrm{Zr}$ impregnated beta zeolite catalyst has been used for the methylation of 2-MN which is the novelty of the present work. In this study, the methylation of 2-MN is carried out in a fixed-bed reactor over beta zeolite (BZ), Cu-impregnated beta zeolite (CuBZ) and $\mathrm{Zr}$-impregnated beta zeolite (ZrBZ) catalysts. The conversion of 2-MN, the ratio of 2,6DMN/2,7-DMN and the selectivity of 2,6-DMN are investigated to demonstrate the activity of the beta type zeolite catalysts.

\section{Experimental}

\subsection{Materials}

Beta zeolite, in granular form (6-8 $\mathrm{mm}$ ), was supplied by ACS Material Corporation (USA). The metal salts such as copper (II) nitrate trihydrate $\left(\mathrm{Cu}\left(\mathrm{NO}_{3}\right)_{2} \cdot 3 \mathrm{H}_{2} \mathrm{O}\right)$ and zirconium (IV) oxynitrate hydrate $\left(\mathrm{ZrO}\left(\mathrm{NO}_{3}\right)_{2} \cdot x \mathrm{H}_{2} \mathrm{O}\right)$ were obtained from Sigma-Aldrich (USA) and Across Organic (USA), respectively.

\subsection{Catalyst preparation}

The ammonium form of beta zeolite catalyst was calcined at $550{ }^{\circ} \mathrm{C}$ for $4 \mathrm{~h}$ to get proton form beta zeolite catalysts (BZ). Next, copper (II) nitrate trihydrate and zirconium (IV) oxynitrate hydrate metals were impregnated into the structure of beta zeolite using a typical wet impregnation method (Güleç et al. 2016, 2017). To prepare Cu-impregnated beta zeolite catalyst (CuBZ), 3.25 gm of copper (II) nitrate trihydrate was dissolved into $20 \mathrm{ml}$ deionized water. After all copper (II) nitrate salt dissolved, $8 \mathrm{gm}$ of BZ was added to the aqueous solution. The mixture was then kept at room temperature overnight for impregnation. After impregnation, the dried solid particles dried at $120{ }^{\circ} \mathrm{C}$ for $4 \mathrm{~h}$ and calcined at $550{ }^{\circ} \mathrm{C}$ for $6 \mathrm{~h}$. The modified catalyst 
was designated as CuBZ. Zr-modified beta zeolite catalyst was prepared exactly the same experimental conditions with using $2.027 \mathrm{gm}$ of zirconium (IV) oxynitrate hydrate and was labeled as ZrBZ. The studies demonstrated that zirconium (IV) oxynitrate hydrate decomposed to the tetragonal phase of $\mathrm{ZrO}_{2}$ (Štefanić et al. 1999), and copper (II) nitrate trihydrate decomposed to $\mathrm{CuO}$ under the experimental conditions that used in this study (Li et al. 2018).

\subsection{Characterization of catalysts}

The scanning electron microscopy (SEM) and energy-dispersive X-ray (EDX) analysis were performed using a ZEISS EVO 40 microscope operated at $20 \mathrm{kV}$. Additionally, the amount of metal loaded on the beta zeolite catalysts surface were measured using a Spectra XLAB-2000 PEDX-ray fluorescence (XRF) spectrometer. The infrared analysis of the catalyst was carried out using a Mattson 1000 Fourier transform infrared spectrometer (FTIR). The FTIR analysis was performed as follows; the pellets $\left(0.109 \mathrm{gm} / \mathrm{cm}^{2}\right)$ were prepared by pressing the sample powders at $10 \mathrm{kPa}$. All of the samples were scanned 30 times per analysis at $16 \mathrm{~cm}^{-1}$ resolution within the $400-4000 \mathrm{~cm}^{-1}$ infrared region. Moreover, the nature of acid sites of the prepared catalysts was characterized by the same FTIR spectroscopy (Py-IR). In the Py-IR experiments, pyridine was used as a probe molecule. Prior to pyridine adsorption, the calcined zeolite catalysts were cooled down to room temperature and located into a desiccator. Pyridine was then dosed onto the samples until saturation, and they were kept in a desiccator for $24 \mathrm{~h}$. The textural properties of prepared beta zeolite catalysts were derived from nitrogen sorption measurements using a Quantachrome NOVA $2200 \mathrm{~N}_{2}$ sorption instrument. The specific surface area of the samples was calculated according to the BET method (Barrett et al. 1951; Fagerlund 1973), and the pore volume was determined using the BJH method (Barrett et al. 1951).

\subsection{Methylation of 2-methylnaphthalene}

Catalytic tests were carried out in a continuous-flow fixedbed reactor as shown in Fig. 1. The experimental setup consists of a high-pressure liquid pump, a nitrogen tube, a flowmeter, a stainless steel tubular fixed-bed flow reactor surrounded by a furnace with a PID temperature controller, a condenser, a phase separator and a GC-MS. The fixedbed reactor was charged with $2 \mathrm{~mL}$ of catalyst in the form of spherical pellets. For activation, the catalyst was pretreated inside the reactor under $\mathrm{N}_{2}$ atmosphere $(5 \mathrm{~mL} / \mathrm{min})$ at $500{ }^{\circ} \mathrm{C}$ for $60 \mathrm{~min}$. The temperature was then set to a value at which the experiment was to be performed. The feed mixture of 2-MN, methanol and 1,3,5-trimethylbenzene (TMB) with a 1:5:5 molar ratio was injected through a high-pressure liquid pump into the fixed-bed reactor at atmospheric pressure.

The temperature of the experiments was varied between 400 and $500{ }^{\circ} \mathrm{C}$. The weight hourly space velocity (WHSV) was changed from 1 to $3 \mathrm{~h}^{-1}$, designated as WHSV1, WHSV2 and WHSV3 for $1 \mathrm{~h}^{-1}, 2 \mathrm{~h}^{-1}$ and $3 \mathrm{~h}^{-1}$, respectively. The reaction products were condensed using a cooler at $-10{ }^{\circ} \mathrm{C}$. The reactants and products were analyzed using a Thermo Finnegan DSQ 250 GC-MS (gas chromatography-mass spectrometry) with a ZB-1 MS capillary column $(60 \mathrm{~m}, 0.25 \mathrm{~mm}$ internal diameter, 0.25 film thickness). The temperature for the injection, MS transfer line and ion source were kept at 280, 300 and $230{ }^{\circ} \mathrm{C}$, respectively. DMN isomers in the products can be easily separated using a column temperature programmer. First, it was heated from 95 to $125{ }^{\circ} \mathrm{C}$ with a ramping of $1{ }^{\circ} \mathrm{C} / \mathrm{min}$, and then from 125 to $200{ }^{\circ} \mathrm{C}$ with a ramping of $5{ }^{\circ} \mathrm{C} / \mathrm{min}$ and finally from 200 to $230{ }^{\circ} \mathrm{C}$ with a ramping of $20{ }^{\circ} \mathrm{C} / \mathrm{min}$ with a $\mathrm{He}$ flow rate of $0.7 \mathrm{~mL} / \mathrm{min}$ as carrier gas.

The conversion of 2-MN (Güleç et al. 2016, 2017; Jin et al. 2006), the selectivity of 2,6-DMN (Niftaliyeva et al. 2015; Güleç et al. 2016, 2017) and the ratio of 2,6-DMN/ 2,7-DMN were determined using the following equations:

Conversion of $2-\mathrm{MN}=\frac{M_{2-\mathrm{MN}, 0}-M_{2-\mathrm{MN}, t}}{M_{2-\mathrm{MN}, 0}} \times 100$

$S_{2,6-\mathrm{DMN}}=\frac{M_{2,6-\mathrm{DMN}}}{M_{\mathrm{DMN}}+M_{\mathrm{TMN}}+M_{\mathrm{MN}}} \times 100$

$R_{2,6 / 2,7}=\frac{M_{2,6-\mathrm{DMN}}}{M_{2,7-\mathrm{DMN}}}$

where $M_{2-\mathrm{MN}, 0}$ and $M_{2-\mathrm{MN}, \mathrm{t}}$ are the mass percentages of $2-\mathrm{MN}$ before and after the reaction, $S_{2,6-\mathrm{DMN}}$ is the selectivity of 2,6-DMN, $\mathrm{M}_{2,6-\mathrm{DMN}}$ is the mass percentage of 2,6DMN after the reaction and $M_{\mathrm{DMN}}$ is the mass percentage of total dimethylnaphthalenes (DMN). $M_{\mathrm{TMN}}$ is the mass percentage of total trimethylnaphthalenes (TMN) after the reaction, $M_{\mathrm{MN}}$ is the mass percentage of total methylnaphthalene (MN, without 2-MN) after the reaction. $M_{2,7}$ DMN is the mass percentage of $2,7-\mathrm{DMN}$ and $R_{2,6 / 2,7}$ is the ratio of 2,6-DMN/2,7-DMN.

\section{Results and discussion}

\subsection{Proposed reaction mechanism}

Methylation of 2-MN was carried out in a fixed-bed reactor over BZ, CuBZ and ZrBZ zeolite catalysts under a nitrogen atmosphere. The possible methylation and isomerization 


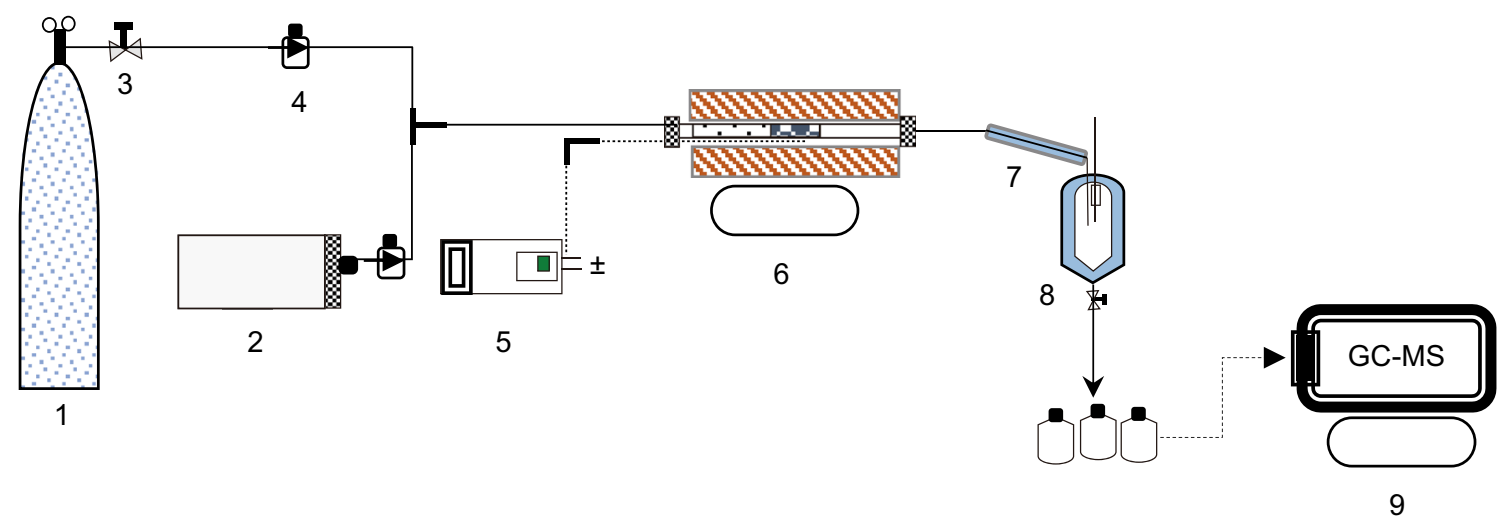

Fig. 1 Schematic representation of experimental setup. 1. Nitrogen tube, 2. high-pressure liquid pump, 3. valve, 4. flowmeter, 5. PID temperature controller, 6. fixed-bed flow reactor, 7. condenser, 8. phase separator, 9. GC-MS

reactions pathways of 2-MN are presented in Fig. 2. The isomerization reaction can occur between methylnaphthalene, dimethylnaphthalene (DMN) and trimethylnaphthalene (TMN) isomers. As for the methylation reaction, it can occur from 2-MN to DMN and/or TMN. Furthermore, $1-\mathrm{MN}$ produced by isomerization of $2-\mathrm{MN}$ may also produce DMN and/or TMN by a methylation reaction. Additionally, DMN isomers can also give a methylation reaction with methanol and produce TMN isomers.

The experimental results support the proposed isomerization reaction from $2-\mathrm{MN}$ to $1-\mathrm{MN}$ and methylation reaction from 2-MN to DMN/TMN (more information presented in the Product distribution section). Additionally, it is known that the beta zeolite catalyst is used for both methylation (Park et al. 2002; Van der Mynsbrugge et al. 2012) and isomerization (Wang et al. 1997; Motoyuki et al. 2000) processes. The methylation from DMN to TMN and isomerization between DMN isomers and TMN isomers has; therefore, a high possibility is shown in proposed reaction mechanism.

\subsection{Surface and chemical characterization of catalysts}

\subsubsection{EDX mapping, SEM and XRF analysis}

The energy-dispersive X-ray (EDX) mapping of untreated beta zeolite catalyst (BZ) and metal impregnated beta zeolite catalysts (CuBZ and $\mathrm{ZrBZ}$ ) is presented in Fig. 3. It is evident from these results that both $\mathrm{Cu}$ and $\mathrm{Zr}$ were successfully impregnated on the beta zeolite structure.

Additionally, the dispersion of metals, $\mathrm{Cu}$ and $\mathrm{Zr}$, on the beta zeolite seemed homogenous. SEM results of untreated and metal impregnated beta zeolite samples are presented in Fig. 4. The EDX mapping and SEM images proved that there was no agglomeration after $\mathrm{Zr}$ impregnation. Additionally, no morphological decomposition was seen on the

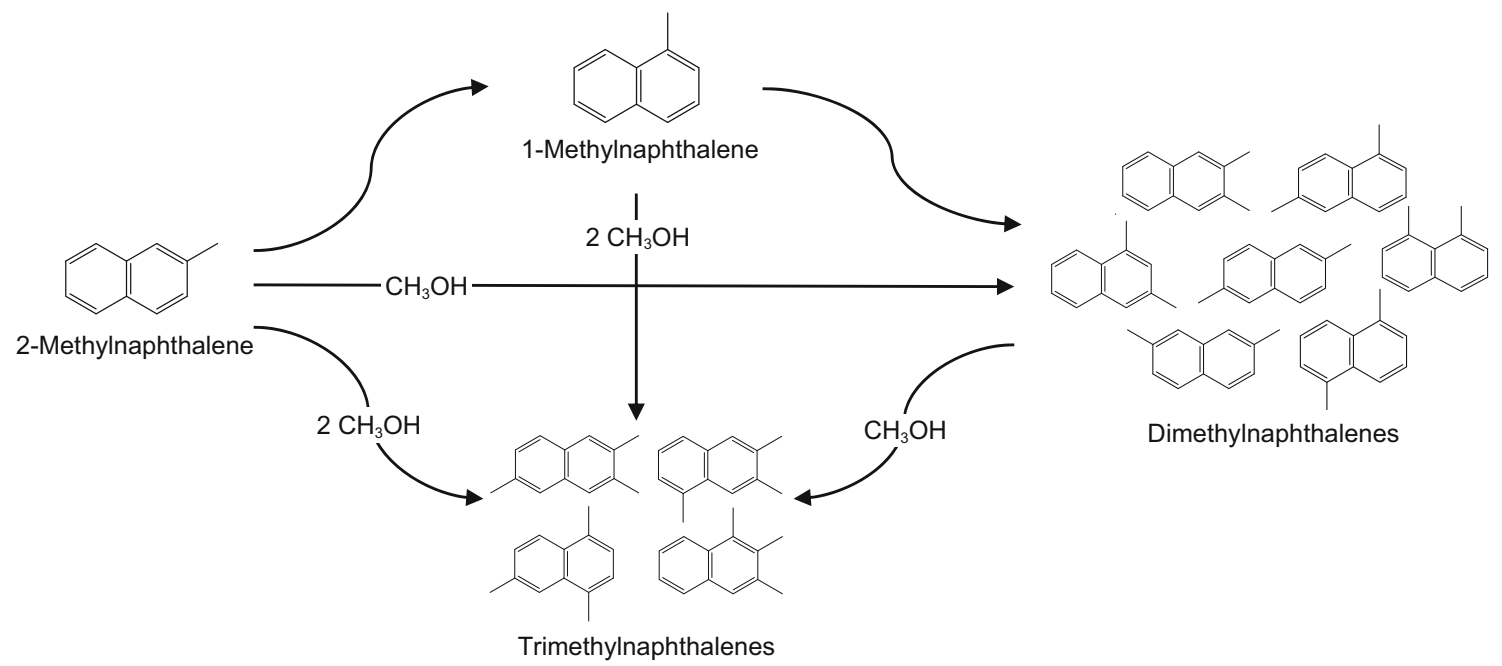

Fig. 2 Possible methylation and isomerization reaction pathways 

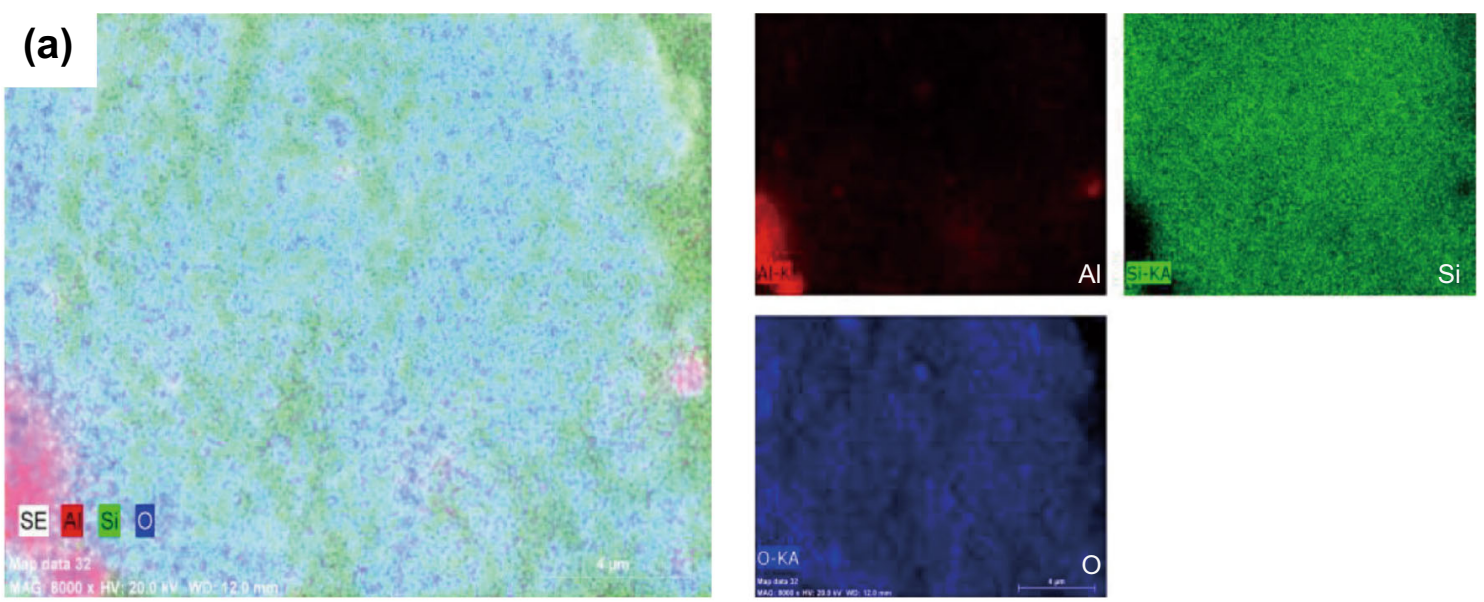

\section{(b)}
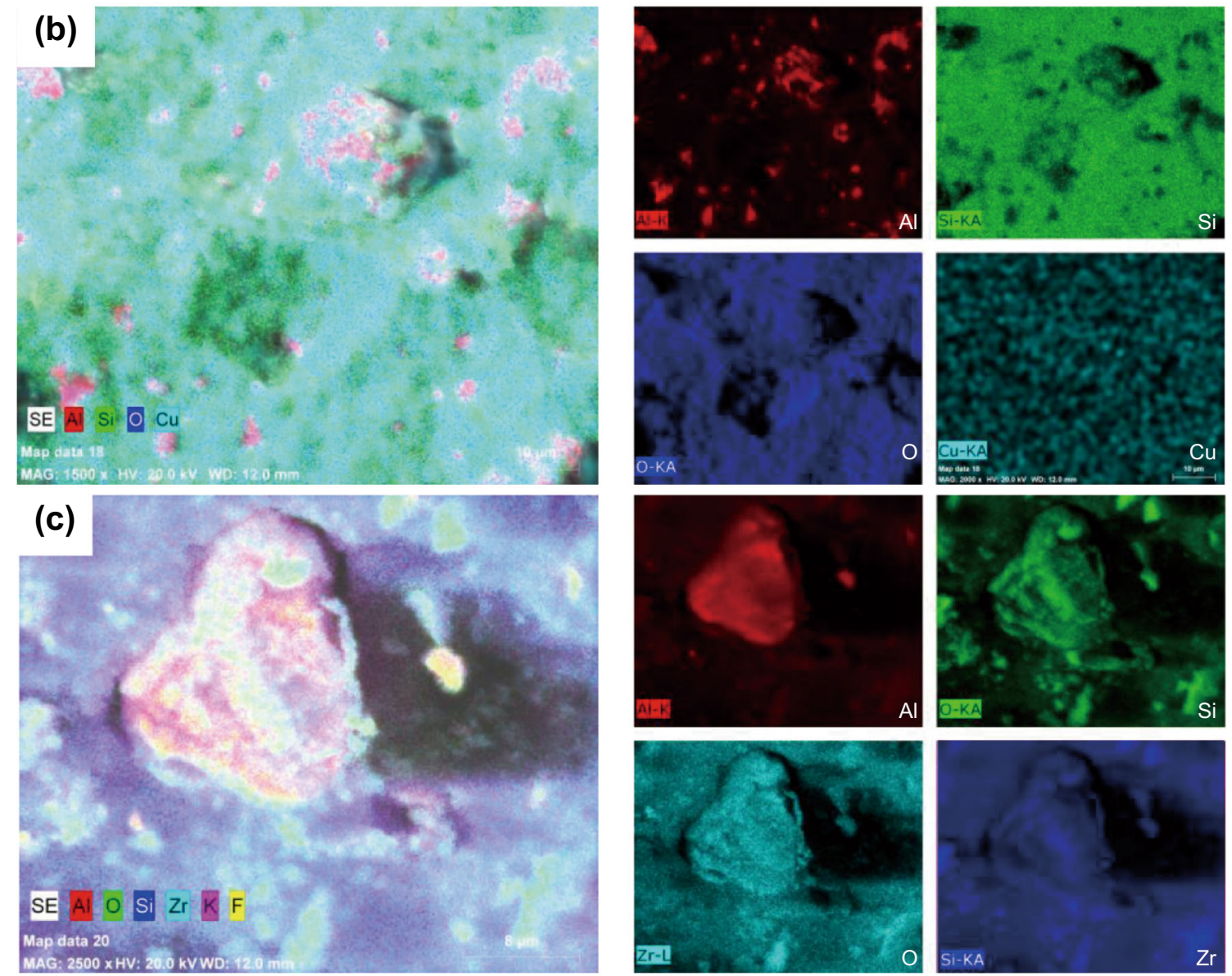

Fig. 3 EDX mapping of untreated beta and metal impregnated beta zeolite catalysts. a BZ, b CuBZ and $\mathbf{c} \mathrm{ZrBZ}$

beta zeolite with $\mathrm{Zr}$ modification (Fig. 4). The amount of impregnated metal was measured by XRF analysis, and results are presented in Table 1. The elemental analysis demonstrates successful impregnation of $\mathrm{Cu}$ and $\mathrm{Zr}$.

\subsubsection{Fourier transform infrared (FTIR) analysis}

The Fourier transform infrared (FTIR) spectrum of all catalysts is presented in Fig. 5. The FTIR spectrum contains a group of absorption bands where the peaks at around 520 and $465 \mathrm{~cm}^{-1}$ indicate the presence of fivemembered double rings, typical of beta zeolite and assigned to vibrations of $\mathrm{T}-\mathrm{O}-\mathrm{T}$ ( $\mathrm{T}$ : $\mathrm{Si}$ or $\mathrm{Al}$ ) siloxane bonds in the rings (Subsadsana et al. 2016; Thakur et al. 2016; Güleç et al. 2016; Shanjiao et al. 2007), respectively. The absorption band at around $805 \mathrm{~cm}^{-1}$ demonstrates internal bonds of the tetrahedral $\mathrm{SiO}_{4}$ structural unit (Güleç et al. 2016). Another band at around $1090 \mathrm{~cm}^{-1}$ indicates 

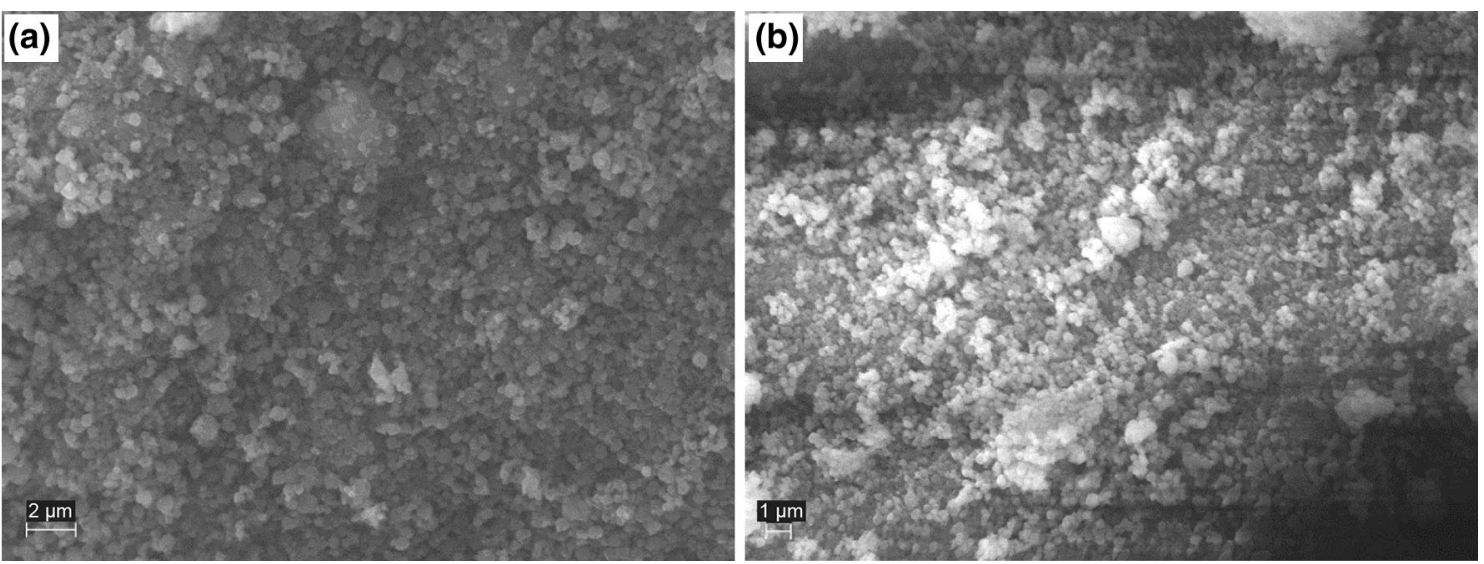

Fig. 4 SEM images of untreated beta and Zr-impregnated beta zeolite catalysts before testing, a BZ, b ZrBZ

Table 1 The elemental analysis of BZ, CuBZ and ZrBZ

\begin{tabular}{lllll}
\hline Properties & $\mathrm{Al}, \%$ & $\mathrm{Si}, \%$ & $\mathrm{Cu}, \mathrm{ppm}$ & $\mathrm{Zr}, \mathrm{ppm}$ \\
\hline BZ & 5.99 & 39.3 & - & - \\
CuBZ & 6.55 & 38.1 & 22,670 & - \\
ZrBZ & 5.70 & 36.9 & - & 19,660 \\
\hline
\end{tabular}

also expressed this idea in their study on the selective synthesis of 2,6-DMN by methylation of 2-MN with methanol over $\mathrm{Zr} /(\mathrm{Al}) \mathrm{ZSM}-5$.

The absorbance values along with Py-IR spectra are presented in Fig. 6. The absorbance values for Lewis (about $1450 \mathrm{~cm}^{-1}$ ), Lewis + Brönsted (about $1495 \mathrm{~cm}^{-1}$ ) and Brönsted (about $1550 \mathrm{~cm}^{-1}$ ) acid sites have not shown

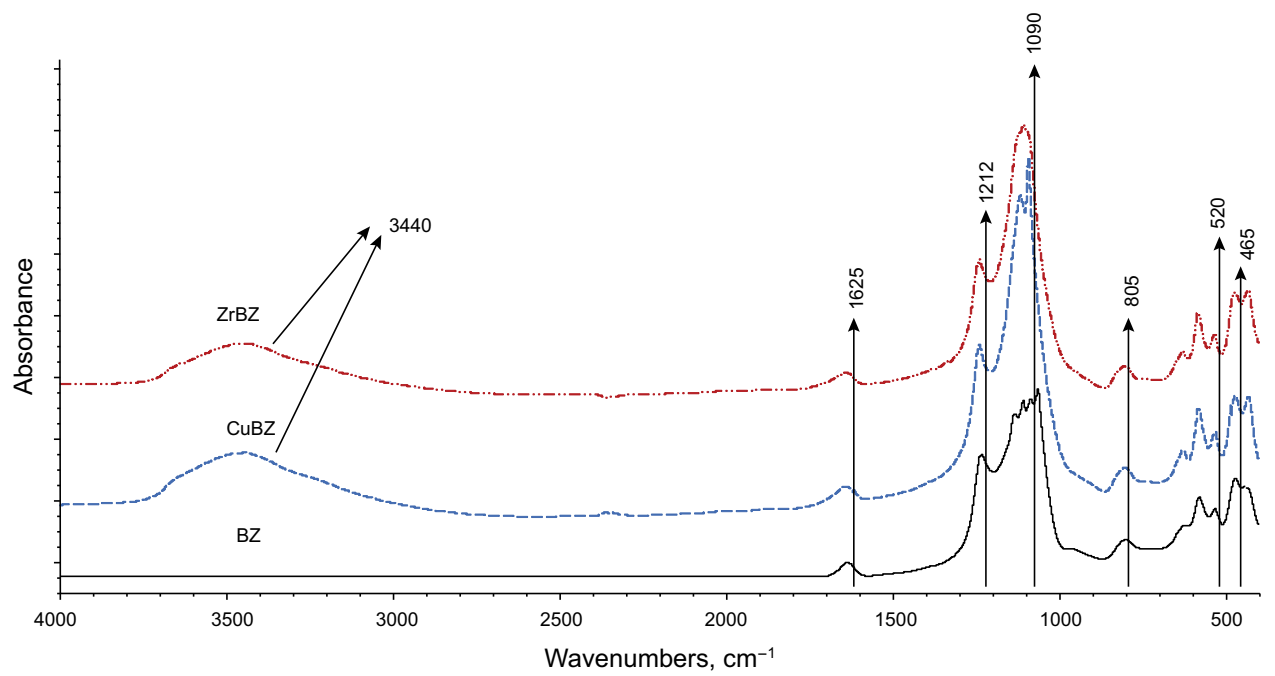

Fig. 5 FTIR spectrum of the BZ, CuBZ and $\mathrm{ZrBZ}$

internal asymmetric stretching of the T-O-T bond (Miao et al. 2016; Thakur et al. 2016; Shanjiao et al. 2007) and the band at about $1212 \mathrm{~cm}^{-1}$ indicates external asymmetric stretching of T-O-T (Thakur et al. 2016). The other wide band at about $3300-3600 \mathrm{~cm}^{-1}$ is associated with $\mathrm{H}$ bonded, O-H groups (Omegna et al. 2004; Miao et al. 2016; Sreedhar et al. 2009; Toktarev et al. 2010). An almost linear decrease was observed in the position of the main TO-T vibrations at about $1100 \mathrm{~cm}^{-1}$ with increasing $\mathrm{Zr}$ content in MFI framework (Szostak 1989). Jin et al. (2006) significant differences with the impregnation of $\mathrm{Cu}$, while they were clearly decreased after the impregnation with $\mathrm{Zr}$. It was noticed that the total acidic amount and proportion of strong acid sites decreased with an increase in the ratio of $\mathrm{Zr} / \mathrm{Al}$, and these findings correlate with those by Jin et al. (2006). 


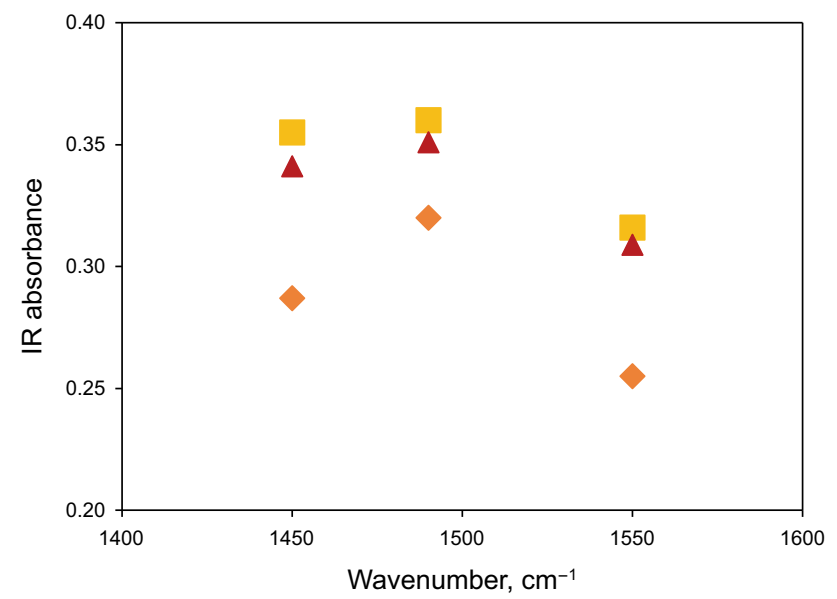

Fig. 6 Py-IR spectra of $\mathrm{Bz}$ (Square), CuBZ (Triangle) and ZrBZ (Diamond)

Table 2 Surface area, pore volume and pore diameter of BZ, CuBZ and $\mathrm{ZrBZ}$ catalysts

\begin{tabular}{lrcc}
\hline Properties & \multicolumn{1}{c}{ BZ } & CuBZ & \multicolumn{1}{c}{ ZrBZ } \\
\hline Surface area $\left(\mathrm{BET}, \mathrm{m}^{2} / \mathrm{g}\right)$ & \multicolumn{1}{c}{424.7} & \multicolumn{1}{c}{406.9} & 427.4 \\
Pore volume $\left(\mathrm{BJH}, \mathrm{cm}^{3} / \mathrm{g}\right)$ & 0.23 & 0.23 & 0.24 \\
Pore diameter $(\mathrm{BJH}, \stackrel{\mathrm{A}}{\mathrm{s}})$ & 30.09 & 30.20 & 37.26 \\
\hline
\end{tabular}

\subsection{3 $\mathrm{N}_{2}$ adsorption-desorption isotherms}

Table 2 presents the surface and pore structure parameters of untreated beta zeolite catalysts (BZ) and metal impregnated beta zeolite catalysts ( $\mathrm{CuBZ}$ and $\mathrm{ZrBZ})$. The BET surface area is slightly decreased from 424 to $406 \mathrm{~m}^{2}$ / $\mathrm{g}$ with $\mathrm{Cu}$ impregnation, while it is insignificantly affected with $\mathrm{Zr}$ modification, $427 \mathrm{~m}^{2} / \mathrm{g}$ as mentioned by (Jin et al. 2006). On the other hand, pore diameter increased with $\mathrm{Cu}$ and $\mathrm{Zr}$ modification.

Figure 7 shows the $\mathrm{N}_{2}$ adsorption-desorption isotherms of the mesoporous beta zeolite catalyst and $\mathrm{Cu}$ - and $\mathrm{Zr}$ impregnated beta zeolite catalysts. According to International Union of Pure and Applied Chemistry (IUPAC) classification, the isotherms may be defined as type IV (Betiha et al. 2015; Jin et al. 2008). In the IUPAC classification, porous materials having a diameter of 20-500 are classified as mesoporous (IUPAC 1997). The isotherms of BZ, CuBZ and ZrBZ contain a hysteresis loop at high $P /$ $P_{0}$ values (higher than 0.4 ) which is typical for mesoporous materials (Egeblad et al. 2017). However, the hysteresis loop of $\mathrm{Cu}$-impregnated beta zeolite catalyst looks slightly different from beta zeolite catalysts, while $\mathrm{Zr}$-impregnated beta zeolite catalyst has a very similar structure. These differences after $\mathrm{Cu}$ impregnation were also observed on the BET surface area results and are shown in Table 2. The
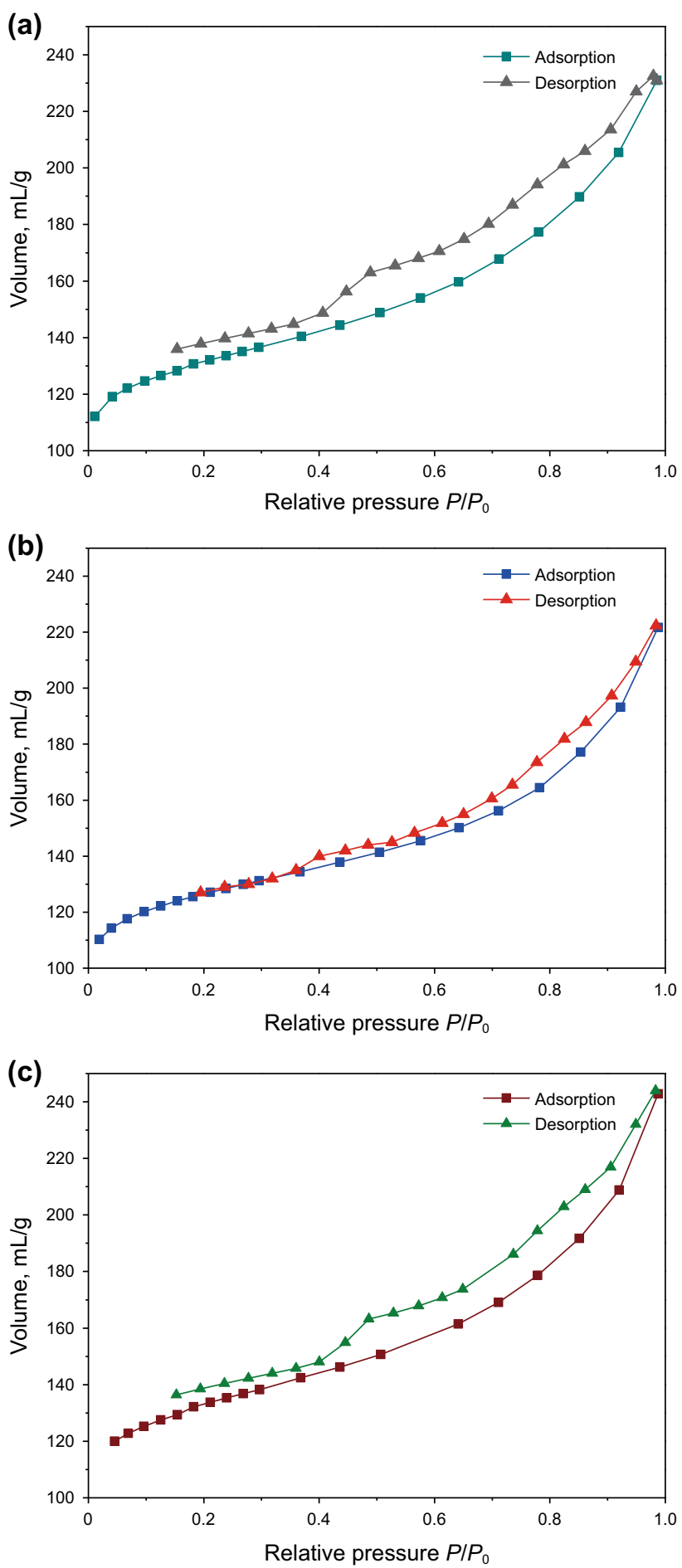

Fig. 7 Nitrogen adsorption-desorption isotherms obtained at $-196{ }^{\circ} \mathrm{C}$; a BZ, b CuBZ and c $\mathrm{ZrBZ}$

characterization results demonstrate the structure of beta zeolite still remains intact after modification with $\mathrm{Zr}$. 


\subsection{Catalytic performance for the methylation of 2-MN}

\subsubsection{Conversion performance of the catalysts}

To demonstrate the activity of the untreated beta zeolite and $\mathrm{Cu}$ - and $\mathrm{Zr}$-impregnated beta zeolite catalysts, the conversion values of 2-MN are calculated using Eq. (1). The conversion rates for $\mathrm{BZ}, \mathrm{CuBZ}$ and $\mathrm{ZrBZ}$ catalysts are presented in Figs. 8, 9 and 10, respectively. Once the beta zeolite catalyst was used for the methylation of 2-MN reaction as a catalyst, the conversion of 2-MN substantially increases with an increase in temperature, but it decreases with increasing WHSV. Figure 10 indicates that when the temperature increases from 400 to $450{ }^{\circ} \mathrm{C}$, the conversion rate sharply increases from $30 \%$ to around $60 \%$ and reaches to about $70 \%$ at $500{ }^{\circ} \mathrm{C}$ for WHSV1 over BZ. On the other hand, at high WHSV conditions, the conversion does not increase as much as it was in the case of WHSV1 for $\mathrm{BZ}$.

Figure 9 represents the conversion of 2-MN when $\mathrm{Cu}-$ modified beta zeolite catalyst was used for the methylation of 2-MN. The conversion trends of 2-MN over CuBZ look almost similar as it is on BZ. The conversion of 2-MN increases from $31 \%$ to $70 \%$ with an increase in temperature from 400 to $500{ }^{\circ} \mathrm{C}$ at WHSV1. At the same temperatures, the conversion of 2-MN also increases from $28 \%$ to $43 \%$ and from $20 \%$ to $30 \%$ at WHSV2 and WHSV3, respectively. Therefore, it could be concluded that $\mathrm{Cu}$ impregnation on beta zeolite catalyst has an insignificant effect on the conversion of 2-MN compared with BZ.

For ZrBZ, Fig. 10 reveals that it is possible to reach much higher conversion rate at low temperatures compared with $\mathrm{CuBZ}$ and $\mathrm{BZ}$ catalysts. The lowest conversion of 2-MN over $\mathrm{ZrBZ}$ is about $50 \%$ at $400{ }^{\circ} \mathrm{C}$ with WHSV3,

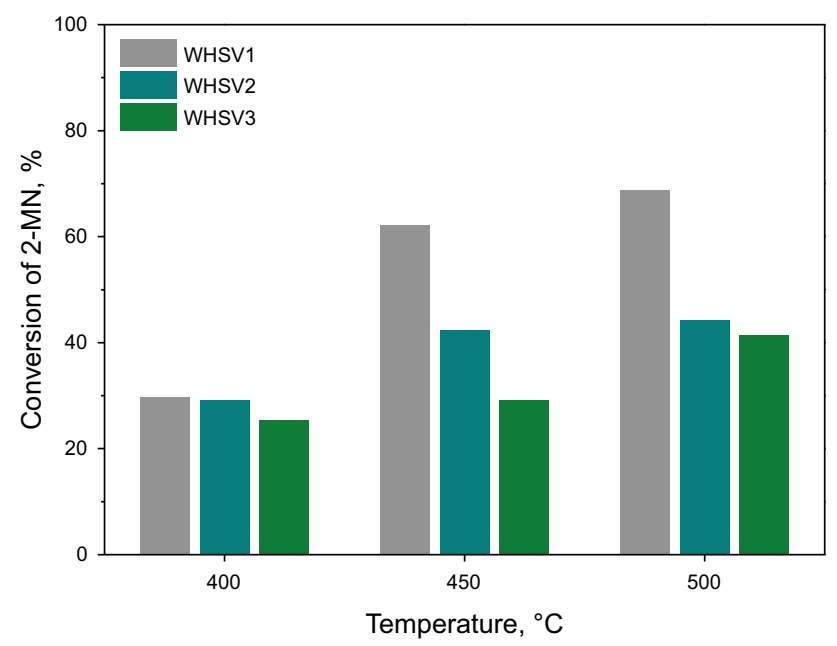

Fig. 8 Conversion of 2-MN at different WHSVs with BZ catalyst

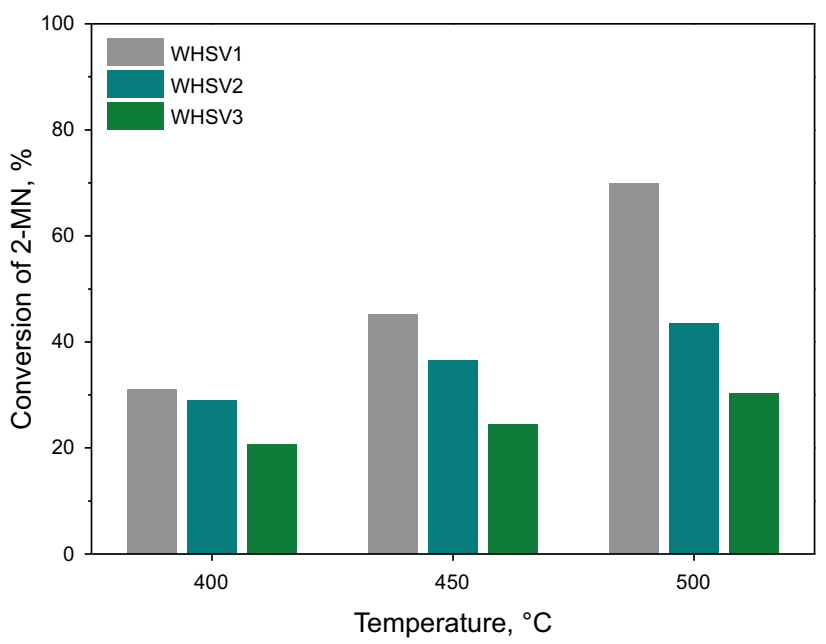

Fig. 9 Conversion of 2-MN at different WHSVs with CuBZ catalyst

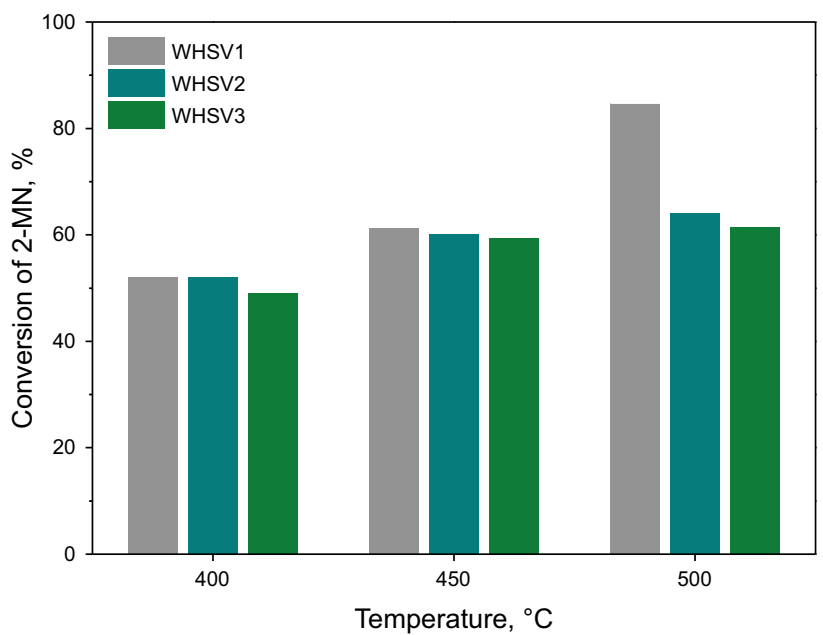

Fig. 10 Conversion of 2-MN at different WHSVs with $\mathrm{ZrBZ}$ catalyst

and the highest conversion is approximately $80 \%$ at $500{ }^{\circ} \mathrm{C}$ with WHSV1. The $\mathrm{Zr}$ impregnation enhances the activity of beta zeolite in terms of methylation reaction of 2-MN compared with the conversion results of BZ. This could be due to the enlargement of pore dimensions and the weakening of Lewis and Brönsted acidities after $\mathrm{Zr}$ impregnation. These findings correlate with those of Jin et al. (2006), where the improvement in the catalytic performance was also mainly attributed to both the weakening of acid strength and the expansion of pore dimensions that occurred after $\mathrm{Zr}$ impregnation into ZSM-5. Moreover, the $\mathrm{Zr}$ impregnation on ZSM-5 has also enhanced the conversion of $2-\mathrm{MN}$ on the disproportionation reaction of 2-MN and similar results are reported by (Güleç et al. 2016). These conversions results of 2-MN for $\mathrm{ZrBZ}$ are also comparable with previous studies ( $\mathrm{Pu}$ and Inui 1996; Jin et al. 2008; Liang et al. 2010; Niftaliyeva et al. 2015; Niftaliyeva and Karaduman 2015; Güleç et al. 2016, 2017; 
Jin et al. 2006). The highest conversion value of 2-MN has been found as $10 \%$ over $\mathrm{Zr} /(\mathrm{Al}) \mathrm{ZSM}-5$ by (Jin et al. 2006), as about $43 \%$ over $8 \mathrm{~h}$ alkaline treated ZSM-5 sample by (Jin et al. 2008) and as 30\% over HZSM-5 by (Güleç et al. 2016). However, these differences in conversion values could also be attributed to different experimental conditions used by different researchers.

\subsubsection{Selectivity analysis of 2,6-DMN}

The selectivity of 2,6-DMN was calculated using Eq. (2), and the results are presented in Figs. 4, 5 and 6 for WHSV1, WHSV2 and WHSV3, respectively. As shown in Fig. 11, the 2,6-DMN selectivity shows a decreasing trend with an increase in temperature at WHSV1. This decrease is from $9 \%$ to $4 \%$ for BZ, $13 \%$ to $6 \%$ for $\mathrm{CuBZ}$ and $14 \%$ to $8 \%$ for $\mathrm{ZrBZ}$ with temperature increasing from 400 to $500{ }^{\circ} \mathrm{C}$ at WHSV1. The increase in the synthesis of other DMN isomers at high temperature could explain this decreasing selectivity of 2,6-DMN at $500{ }^{\circ} \mathrm{C}$. A higher 2,6DMN selectivity is obtained on both $\mathrm{Cu}$ - and $\mathrm{Zr}$-impregnated beta zeolite catalysts compared with untreated beta zeolite at WHSV1.

Similar decreasing trends in the selectivity with increasing temperature were also noticed at WHSV2 as can be seen in Fig. 12. However, when the weight hourly space velocity increases from WHSV1 to WHSV2, the selectivity of 2,6-DMN starts increasing for both BZ and $\mathrm{ZrBZ}$, while it demonstrates a clear decrease for CuBZ. The selectivity increased from $14 \%$ to $20 \%$ for $\mathrm{ZrBZ}$ but decreased from $13 \%$ to $7 \%$ for $\mathrm{CuBZ}$ at $400{ }^{\circ} \mathrm{C}$ with increasing WHSV from 1 to $2 \mathrm{~h}^{-1}$. Therefore, the $\mathrm{Zr}$ modification enhanced 2,6-DMN selectivity, but on the other hand, $\mathrm{Cu}$ impregnation decreased the selectivity at WHSV2. According to Fig. 13, when the weight hourly space velocity increased

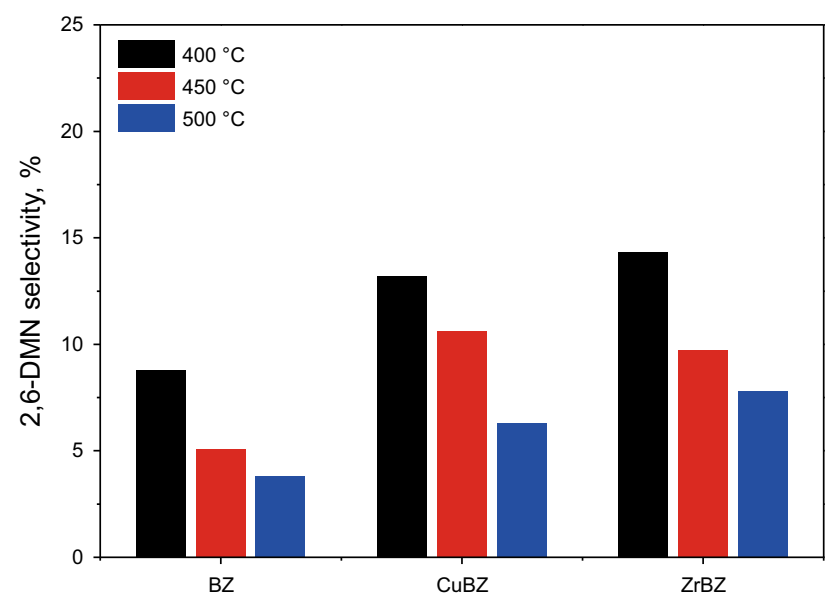

Fig. 11 The selectivity of 2,6-DMN at different temperatures with WHSV1

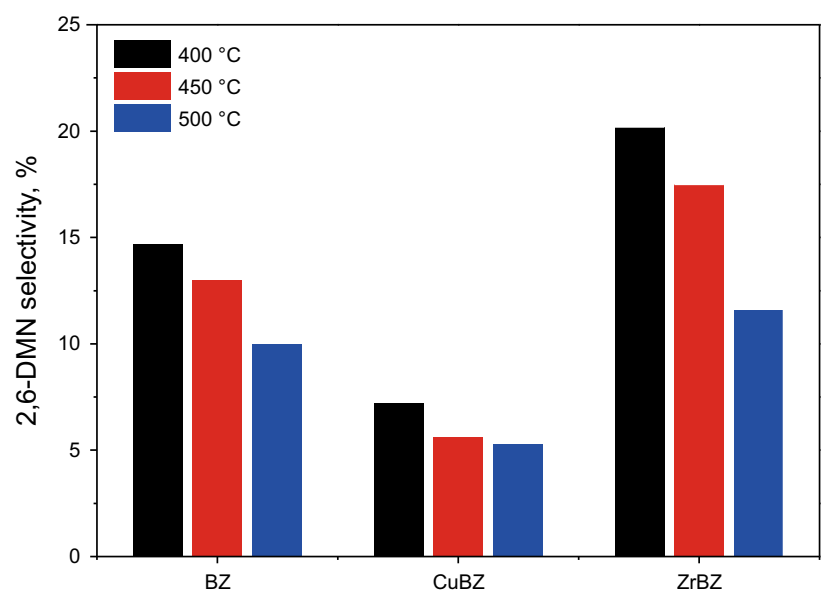

Fig. 12 The selectivity of 2,6-DMN at different temperatures with WHSV2

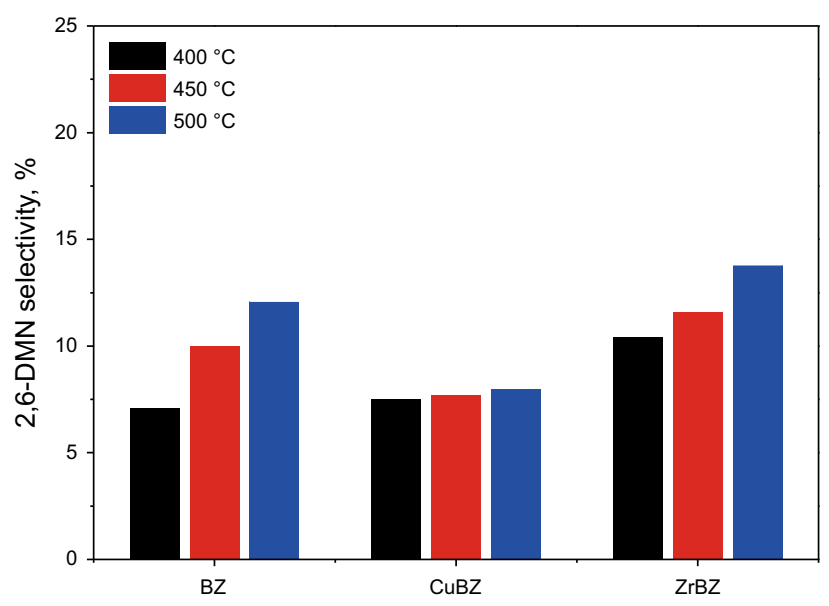

Fig. 13 The selectivity of 2,6-DMN at different temperatures with WHSV3

from 2 to $3 \mathrm{~h}^{-1}$, the selectivity of 2,6-DMN decreased over $\mathrm{BZ}, \mathrm{CuBZ}$ and $\mathrm{ZrBZ}$ at 400 and $450^{\circ} \mathrm{C}$. However, it was slightly higher at $500{ }^{\circ} \mathrm{C}$ over BZ, CuBZ and $\mathrm{ZrBZ}$.

In general, ZrBZ showed higher selectivity at low temperature, $400{ }^{\circ} \mathrm{C}$, compared with BZ and CuBZ. Furthermore, the highest 2,6-DMN selectivity, about $20 \%$, was attained over $\mathrm{Zr}$-modified beta zeolite catalyst at $400{ }^{\circ} \mathrm{C}$ with WHSV2. These selectivity results of 2,6-DMN also correlate with the findings of Jin et al. (2006) where they mentioned that when a small quantity of $\mathrm{Zr}$ is incorporated in the framework of ZSM-5, the selectivity of 2,6-DMN is obviously improved in the methylation of 2-MN.

\subsubsection{The ratio of 2,6-DMN to 2,7-DMN}

The ratio of 2,6-DMN/2,7-DMN at different temperatures is presented in Fig. 14. The ratio of 2,6-DMN/2,7-DMN is generally greater than 1.0 for $\mathrm{BZ}, \mathrm{CuBZ}$ and $\mathrm{ZrBZ}$ zeolite 

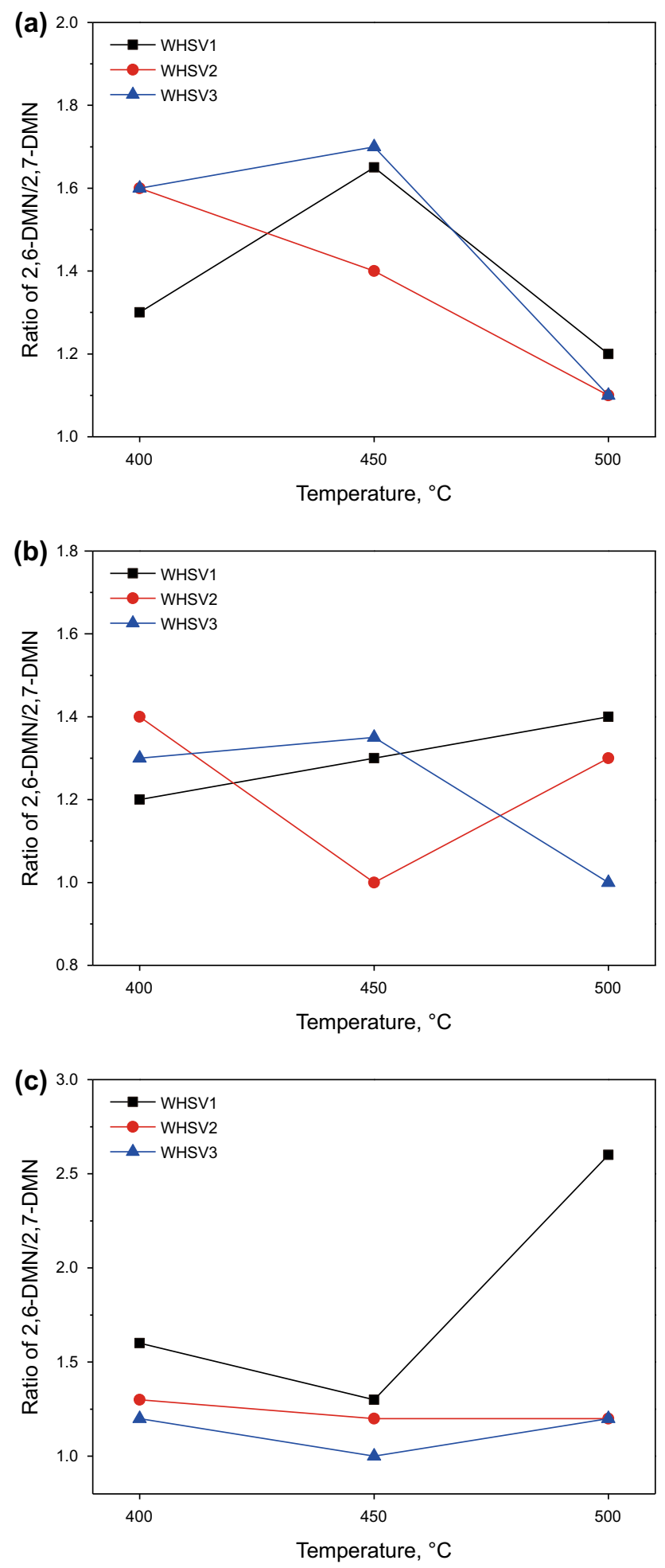

Fig. 14 The ratio of 2,6-DMN to 2,7-DMN at different WHSVs over a $\mathrm{BZ}$, b $\mathrm{CuBZ}$ and $\mathbf{c} \mathrm{ZrBZ}$

catalysts. The higher ratio of 2,6-DMN/2,7-DMN can enable an easy subsequent separation because a eutectic mixture would be formed at a ratio of 0.7 (Millini et al. 2003). However, a decrease in the ratio of 2,6-DMN/2,7-
DMN was noticed after both $\mathrm{Cu}$ and $\mathrm{Zr}$ impregnation on beta zeolite at $400{ }^{\circ} \mathrm{C}$ and $450{ }^{\circ} \mathrm{C}$ for WHSV2 and WHSV3. Generally, the ratio of 2,6-DMN/2,7-DMN is higher than 1.0. Moreover, an increase in the ratio can be observed over $\mathrm{Cu}$ and $\mathrm{Zr}$ impregnation at $500{ }^{\circ} \mathrm{C}$ for WHSV1. While a great increase in the ratio about 2.5-3.0 of 2,6-DMN/2,7-DMN after $\mathrm{Zr}$ impregnation on ZSM-5 was investigated by Jin et al. (2006), where $\mathrm{Zr}$ impregnation on beta zeolite catalysts has not much effect on the ratio. The ratio of 2,6-DMN/2,7-DMN is between 1.1 and 1.7 for BZ, 1.0 and 1.4 for CuBZ and 1.2-2.6 for $\mathrm{ZrBZ}$ as shown in Fig. 14.

\subsubsection{Product distribution}

The weight percentage distributions of 1-MN and DMN isomers in the product stream are provided in Table 3 . The production distribution results are at WHSV2 space velocity conditions where the highest 2,6-DMN selectivity was achieved. The 2,6-DMN and other DMN isomers such as 2,7-DMN, 1,3-DMN, 1,2-DMN and 2,3-DMN are synthesized with methylation of 2-MN over BZ, CuBZ and $\mathrm{ZrBZ}$. It is clear that the beta zeolite catalyst and $\mathrm{Cu}-$ and Zr-impregnated beta zeolite catalysts have a selective shape for both 1,3-DMN and 2,6-DMN. These two isomers are the highest among the other DMN isomers for both beta zeolite catalyst and metal impregnated beta zeolite catalysts used in the present study. The amount of 2,6-DMN is dramatically increased from a low value, $0.20 \%$ and $0.37 \%$, to very high value, $2.42 \%$ and $2.20 \%$, when temperature increased from 400 to $500{ }^{\circ} \mathrm{C}$ for both $\mathrm{BZ}$ and CuBZ, respectively.

As mentioned before, the $\mathrm{Cu}$ impregnation has an insignificant effect on the synthesis of 2,6-DMN with methylation of 2-MN. However, the $\mathrm{Zr}$ impregnation has an important effect on the synthesis of DMN especially 1,3-DMN and 2,6-DMN. For example, the weight percentage of 2,6-DMN is about $2.58 \%$ at $400{ }^{\circ} \mathrm{C}$ which is 10 times higher than $\mathrm{BZ}$ and almost 7 times higher than $\mathrm{CuBZ}$ at the same temperature. In addition to DMN isomers, $1-\mathrm{MN}$ is also synthesized by isomerization of 2-MN. The percentage of $1-\mathrm{MN}$ in the product stream increases when the temperature increased from 400 to $500{ }^{\circ} \mathrm{C}$, also shown in Table 3. Over CuBZ, the weight percentage of $1-\mathrm{MN}$ is about 10 times higher at $500{ }^{\circ} \mathrm{C}$ than as it was at $400{ }^{\circ} \mathrm{C}$. It was explained by the acid strength differences of the catalyst in the alkylation and isomerization reactions by Komatsu et al. (1999). Weak acid sites only catalyze the alkylation while the isomerization reaction tends to occur in the presence of strong acid sites. The increase in the selectivity of DMN isomers thanks to the $\mathrm{Zr}$ impregnation might be attributed to the weak acid sites while the increase 
Table 3 Distributions 1-MN and DMN isomers over BZ, $\mathrm{CuBZ}$ and $\mathrm{ZrBZ}$ at different temperatures and WHSV2

\begin{tabular}{|c|c|c|c|c|c|c|c|c|c|}
\hline & \multicolumn{9}{|c|}{ Content in the product stream, wt $\%$} \\
\hline & \multicolumn{3}{|l|}{$\mathrm{BZ}$} & \multicolumn{3}{|l|}{$\mathrm{CuBZ}$} & \multicolumn{3}{|l|}{$\mathrm{ZrBZ}$} \\
\hline Temperature, ${ }^{\circ} \mathrm{C}$ & 400 & 450 & 500 & 400 & 450 & 500 & 400 & 450 & 500 \\
\hline \multicolumn{10}{|l|}{ Methylnaphthalene } \\
\hline $1-\mathrm{MN}$ & 1.55 & 1.75 & 4.00 & 1.46 & 4.55 & 14.71 & 4.49 & 5.04 & 6.85 \\
\hline \multicolumn{10}{|c|}{ Dimethylnaphthalenes } \\
\hline 2,6-DMN & 0.20 & 1.08 & 2.42 & 0.37 & 0.53 & 2.20 & 2.58 & 2.92 & 3.77 \\
\hline 2,7-DMN & 0.12 & 0.77 & 2.12 & 0.27 & 0.52 & 1.76 & 2.00 & 2.42 & 3.10 \\
\hline $1,3-\mathrm{DMN}$ & 0.34 & 1.70 & 4.98 & 0.42 & 0.30 & 3.01 & 4.91 & 4.72 & 6.86 \\
\hline $1,2-\mathrm{DMN}$ & - & 0.53 & 1.30 & 0.15 & 0.17 & 0.68 & 1.17 & 1.08 & 1.75 \\
\hline 2,3-DMN & 0.16 & 1.11 & 2.98 & 0.20 & 0.11 & 0.25 & 0.23 & 0.23 & 0.05 \\
\hline
\end{tabular}

in the 1-MN once CuBZ is used in the methylation of 2-MN may be attributed to the strong acid sites.

Although TMN isomers were also synthesized by the methylation of 2-MN, the percentages of TMN are not presented in this paper due to the low amounts. The defined products in the product stream prove both the isomerization reaction from 2-MN to $1-\mathrm{MN}$ and the methylation reaction from 2-MN to DMN/TMN isomers. Therefore, the proposed reaction mechanism presented is supported by the experimental results.

\section{Conclusions}

The effects of $\mathrm{Cu}$ - and $\mathrm{Zr}$-impregnated beta zeolite catalysts on the methylation of 2-MN were experimentally investigated. 2-MN conversion increases with an increase in the temperature and decreases with an increase in the WHSV for BZ, CuBZ and ZrBZ. The conversion reached a peak level at $500{ }^{\circ} \mathrm{C}$ and WHSV1 for all three catalysts: $\mathrm{BZ}, \mathrm{ZrBZ}$ and CuBZ. However, the highest conversion was reached on $\mathrm{Zr}$-modified beta zeolite catalyst at both low and high temperatures. In addition to the conversion, the highest 2,6-DMN selectivity of about $20 \%$ and the highest ratio of 2,6-DMN/2,7-DMN of about 2.6 were also achieved over ZrBZ. In addition to 2,6-DMN, the other DMN isomers such as 2,7-DMN, 1,3-DMN, 1,2-DMN and 2,3-DMN are also synthesized with methylation of 2-MN. The beta zeolite structure is more selective for 1,3-DMN and 2,6-DMN compared to other DMN isomers. The $\mathrm{Cu}$ impregnation enhanced the isomerization reaction from $2-\mathrm{MN}$ to $1-\mathrm{MN}$, whereas the $\mathrm{Zr}$ impregnation improved the methylation reaction from 2-MN to DMN isomers, mainly 1,3-DMN and 2,6-DMN.

For the future work, lower weight hourly space velocities are suggested to increase the selectivity of 2,6-DMN. Moreover, two serial fixed-bed reaction systems could be investigated to increase the selectivity of 2,6-DMN and the conversion rate. Furthermore, a cheap naphthalene source such as the coal tar naphthalene oil fraction which is a waste product of the iron and steel industry could be used as a raw material which could bring down the production cost of 2,6-DMN.

Acknowledgements This work is supported by The Scientific and Technological Research Council of Turkey [TÜBİTAK Project No. 112M297].

Open Access This article is distributed under the terms of the Creative Commons Attribution 4.0 International License (http://creative commons.org/licenses/by/4.0/), which permits unrestricted use, distribution, and reproduction in any medium, provided you give appropriate credit to the original author(s) and the source, provide a link to the Creative Commons license, and indicate if changes were made.

\section{References}

Bai X, Sun K, Wu W, Yan P, Yang J. Methylation of naphthalene to prepare 2,6-dimethylnaphthalene over acid-dealuminated HZSM-12 zeolites. J Mol Catal A Chem. 2009;314(1-2):81-7. https://doi.org/10.1016/j.molcata.2009.08.020.

Barrett EP, Joyner LG, Halenda PP. The determination of pore volume and area distributions in porous substances. I. Computations from nitrogen isotherms. J Am Chem Soc. 1951;73(1):373-80.

Betiha MA, Menoufy MF, Al-Sabagh AM, Hassan HM, Mahmoud SA. Acidic mesostructured aluminosilicates assembled from economic acidic template characterized by catalytic cracking reactions. Microporous Mesoporous Mater. 2015;204:15-24. https://doi.org/10.1016/j.micromeso.2014.10.043.

Egeblad K, Kustova M, Klitgaard SK, Zhu K, Christensen $\mathrm{CH}$. Mesoporous zeolite and zeotype single crystals synthesized in fluoride media. Microporous Mesoporous Mater. 2017;101(1-2):2014-223. https://doi.org/10.1016/j.micromeso. 2006.11.001.

Fagerlund G. Determination of specific surface by the BET method. Matériaux et Constr. 1973;6(3):239-45. https://doi.org/10.1007/ BF02479039.

Ferino I, Monaci R, Pedditzi L, Rombi E, Solinas V. Isomerization of dimethylnaphthalenes over zeolites. React Kinet Catal L. 1996;58(2):307-14. https://doi.org/10.1007/BF02067038. 
Fraenkel D, Cherniavsky M, Ittah B, Levy M. Shape-selective alkylation of naphthalene and methylnaphthalene with methanol over H-ZSM-5 zeolite catalysts. J Catal. 1986;101(2):273-83. https://doi.org/10.1016/0021-9517(86)90254-X.

Güleç F, Özen A, Niftaliyeva A, Aydın A, Şimşek EH, Karaduman A. A kinetic study on methylation of naphthalene over Fe/ZSM-5 zeolite catalysts. Res Chem Intermediat. 2017;44(1):55-67. https://doi.org/10.1007/s11164-017-3090-5.

Güleç F, Şimşek EH, Karaduman A. Disproportionation kinetics of 2-methylnaphthalene in the presence of Zr/ZSM5 zeolite catalysts. J Fac Eng Archit Gaz. 2016;31(3):610-21. https://doi.org/ 10.17341/gummfd.93160.

Jin L, Fang Y, Hu H. Selective synthesis of 2,6-dimethylnaphthalene by methylation of 2-methylnaphthalene with methanol on $\mathrm{Zr} /$ (Al) ZSM-5. Catal Commun. 2006;7(5):255-9. https://doi.org/ 10.1016/j.catcom.2005.11.012.

Jin L, Zhou X, Hu H, Ma B. Synthesis of 2,6-dimethylnaphthalene by methylation of 2-methylnaphthalene on mesoporous ZSM-5 by desilication. Catal Commun. 2008;10(3):336-40. https://doi.org/ 10.1016/j.catcom.2008.09.024.

Komatsu T, Kim JH, Yashima T. MFI-type metallosilicates as useful tools to clarify what determines the shape selectivity of ZSM-5 zeolites. ACS Publ. 1999;738(11):162-80. https://doi.org/10. 1021/bk-2000-0738.ch011.

Li C, Ma J, Xiao Z, Hector SB, Liu R, Zuo S, Liu Q. Catalytic cracking of Swida wilsoniana oil for hydrocarbon biofuel over Cu-modified ZSM-5 zeolite. Fuel. 2018;218:59-66. https://doi. org/10.1016/j.fuel.2018.01.026.

Liang Z, Xinwen G, Min L, Xiangsheng W, Chunshan S. Methylation of 2-Methylnaphthalene with Methanol over $\mathrm{NH}_{4} \mathrm{~F}$ and $\mathrm{Pt}$ Modified HZSM-5 Catalysts. Chin J Chem Eng. 2010;18(5):742-9. https://doi.org/10.1016/S10049541(09)60123-3.

Miao Q, Zhao B, Liu S, Guo J, Tong Y, Cao J. Decomposition of the potassic rocks by sub-molten salt method and synthesis of low silica X zeolite. Asia-Pac J Chem Eng. 2016;11(4):558-66. https://doi.org/10.1002/apj.1980.

Millini R, Frigerio F, Bellussi G, Pazzuconi G, Perego C, Pollesel P, Romano U. A priori selection of shape-selective zeolite catalysts for the synthesis of 2,6-dimethylnaphthalene. J Catal. 2003;217(2):298-309. https://doi.org/10.1016/S00219517(03)00071-X.

Motoyuki M, Yamamoto K, Yoshida S, Yamamoto S, Sapre AV, Mc Williams JP, Hellring SD. Isomerization of dimethylnaphthalene to produce 2,6-dimethylnaphthalene: US Patent 6,018,087, issued January 25, 2000.

Niftaliyeva A, Güleç F, Şimşek EH, Güllü M, Karaduman A. Cu-Y ve La-Y Zeolit Katalizörleri Üzerinde 2-metilnaftalinin metilasyon Kinetiği. Ananadolu Univ J Sci Technol-A Appl Sci Eng. 2015;16(2):167-78. https://doi.org/10.18038/btd-a.93009.

Niftaliyeva A, Karaduman A. Y Zeolit Katalizörünün 2-Metil Naftalinin Disproporsiyonuna Katalitik Etkisi. Ananadolu University J Sci Technol A Appl Sci Eng. 2015;16(2):275-82. https://doi.org/10.18038/btd-a.55257.

Omegna A, Vasic M, van Bokhoven JA, Pirngruber G, Prins R. Dealumination and realumination of microcrystalline zeolite beta: an XRD, FTIR and quantitative multinuclear (MQ) MAS NMR study. Phys Chem Chem Phys. 2004;6(2):447-52. https:// doi.org/10.1039/B311925D.

Park JN, Wang J, Hong SI, Lee CW. Effect of dealumination of zeolite catalysts on methylation of 2-methylnaphthalene in a high-pressure fixed-bed flow reactor. Appl Catal A Gen. 2005;292:68-75. https://doi.org/10.1016/j.apcata.2005.05.039.

Park JN, Wang J, Lee CW, Park SE. Methylation of naphthalene with methanol over beta, mordernite, ZSM-12 and MCM-22 zeolite catalysts. Bull Korean Chem Soc. 2002;23(7):1011-3. https:// doi.org/10.5012/bkcs.2002.23.7.1011.

$\mathrm{Pu} \mathrm{SB}$, Inui T. Synthesis of 2, 6-dimethylnaphthalene by methylation of methylnaphthalene on various medium and large-pore zeolite catalysts. Appl Catal A Gen. 1996;146(2):305-16. https://doi. org/10.1016/S0926-860X(96)00182-2.

Shanjiao K, Yanjun G, Tao D, Ying Z, Yanying Z. Preparation and characterization of zeolite beta with low $\mathrm{SiO}_{2} / \mathrm{Al}_{2} \mathrm{O}_{3}$ ratio. Petrol Sci. 2007;4(1):70-4. https://doi.org/10.1007/BF03186577.

Song C, Shen JP, Reddy KM, Sun L, Lillwitz LD. Shape-selective FeMFI catalyst for synthesis of 2, 6-dimethylnaphthalene by methylation with methanol. Stud Surf Sci Catal. 2007;170:1275-82. https://doi.org/10.1016/S01672991(07)80988-8.

Sreedhar I, Reddy KSK, Raghavan K. Studies on physico-chemical changes in zeolite beta in mononitration of toluene. Kinet Catal. 2009;50(1):131-7. https://doi.org/10.1134/S0023158409010170.

Štefanić G, Gržeta B, Popović S, Musić S. In situ phase analysis of the thermal decomposition products of zirconium salts. Croat Chem Acta. 1999;72(2-3):395-412.

Subsadsana M, Sangdara P, Ruangviriyachai C. Effect of bimetallic NiW modified crystalline ZSM-5 zeolite on catalytic conversion of crude palm oil and identification of biofuel products. Asia-Pac J Chem Eng. 2016;12(1):147-58. https://doi.org/10.1002/apj. 2061.

Szostak R. Molecular sieves. New York: Van Nostrand Reihold; 1989. https://doi.org/10.1007/978-94-010-9529-7.

Thakur R, Barman S, Gupta RK. Synthesis of cumene by transalkylation over modified beta zeolite: a kinetic study. Braz J Chem Eng. 2016;33(4):957-67. https://doi.org/10.1590/0104-6632. 20160334 s20150333.

Toktarev A, Malysheva L, Paukshtis E. Effect of thermal treatment conditions on the acid properties of zeolite Beta. Kinet Catal. 2010;51(2):318-24. S0023158410020229.

UPAC. Compendium of Chemical Terminology (A. D. M. A. A. Wilkinson Ed. 2nd ed. (the "Gold Book")). Oxford: Blackwell Scientific Publications, 1997.

Van der Mynsbrugge J, Visur M, Olsbye U, Beato P, Bjørgen M, Van Speybroeck V, Svelle S. Methylation of benzene by methanol: single-site kinetics over H-ZSM-5 and H-beta zeolite catalysts. J Catal. 2012;292:201-12. https://doi.org/10.1016/j.jcat.2012.05. 015 .

Wang ZB, Kamo A, Yoneda T, Komatsu T, Yashima T. Isomerization of $n$-heptane over Pt-loaded zeolite $\beta$ catalysts. Appl Catal A Gen. 1997;159(1-2):119-32. https://doi.org/10.1016/S0926860X(97)00059-8.

Wu W, Weiguo W, Kikhtyanin OV, Lingfei L, Toktarev AV, Ayupov AB, Khabibulin JF, Echevsky GV, Huang J. Methylation of naphthalene on MTW-type zeolites. Influence of template origin and substitution of Al by Ga. Appl Catal A Gen. 2010;375(2):279-88. https://doi.org/10.1016/j.apcata.2010.01. 003.

Zhang C, Guo XW, Wang YN, Wang XS, Song CS. Methylation of 2-methylnaphthalene with methanol to 2, 6-dimethylnaphthalene over HZSM-5 modified by $\mathrm{NH}_{4} \mathrm{~F}$ and $\mathrm{SrO}$. Chin Chem L. 2007;18(10):1281-4. https://doi.org/10.1016/j.cclet.2007.07. 025 .

Zhao L, Wang H, Liu M, Guo X, Wang X, Song C, Liu H. Shapeselective methylation of 2-methylnaphthalene with methanol over hydrothermal treated HZSM-5 zeolite catalysts. Chem Eng Sci. 2008;63(21):5298-303. https://doi.org/10.1016/j.ces.2008. 07.018. 